\title{
Pemetaan Jalur Transportasi Bus Umum Kota Batam Menggunakan QuantumGIS dan Geoserver
}

\author{
Dwi Ely Kurniawan ${ }^{1, *}$, Eka Indra Setiaji ${ }^{2}$ \\ 1,2 Jurusan Teknik Informatika Politeknik Negeri Batam \\ J. Ahmad Yani Batam Center, Batam \\ (corresponding author) dwialikhs@polibatam.ac.id*
}

\begin{abstract}
Batam is a growing city with industry and trade, in which the means of transport has an important role in the movement and displacement. One of the companies engaged in public transportation services is Bus Damri. Bus Damri Batam now starting to grow and the demand by the user. However, some users complained of related information service or the path of a bus, destination and where the bus shelter can be found. WebGIS-based system is one of the alternative communication media in the form of spatial or map on a web. Digitizing the form of spatial coordinates of points, lines and polygons using open source software QuantumGIS. Web server used is GeoServer, the excess is easy to integrate spatial data because it supports many types of data formats and functionality of vector, raster and database. Software development methods using linear sequential systems, starting from planning, analysis, design, code, test and implementation. The next step is to conduct georeferenced, digitized and store it in the form shapfile, then upload to the web server. Testing is done by examining and observing the execution results through the test data from software that has been developed. Results and implementation of the development system can help users find the bus stop, the bus line and destination.
\end{abstract}

Keyword- Bus Line, QuantumGIS, GeoSenver.

Intisari- Batam merupakan kota yang sedang berkembang dengan industri dan perdagangan, dimana sarana transportasi memiliki peranan penting dalam pergerakan dan perpindahan. Salah satu perusahaan yang bergerak pada jasa transportasi umum adalah Bus Damri. Bus Damri Kota Batam saat ini mulai berkembang dan diminati oleh pengguna. Namun beberapa pengguna mengeluhkan informasi terkait rute atau jalur yang dilalui bus, tujuan dan di mana saja selter bus dapat ditemui. Sistem berbasis webGIS merupakan salah satu alternatif media penyampaian informasi dalam bentuk spasial atau peta pada sebuah web. Digitasi keruangan berupa koordinat titik, garis dan polygon menggunakan perangkat lunak open source QuantumGIS. Web server yang digunakan adalah Geoserver, kelebihannya mudah dalam mengintegrasikan data spasial karena mendukung banyak tipe format dan fungsionalitas data vector, raster dan basis data. Metode pengembangan perangkat lunak menggunakan sistem sekuensial linear, dimulai dari perencanaan, analisis, desain, kode, pengujian dan implementasi. Tahap perencanaan melakukan analisis kebutuhan pengguna dan survei data titik koordinat lokasi halte dan jalur bus. Selanjutnya tahap desain dan kode adalah melakukan georeferensi, digitasi dan menyimpannya dalam bentuk shapfile, kemudian mengunggah ke web server. Pengujian dilakukan dengan memeriksa dan mengamati hasil eksekusi melalui data uji dari perangkat lunak yang telah dikembangkan. Hasil dan implementasi dari pengembangan sistem dapat membantu pengguna dalam mencari halte, jalur dan tujuan bus tersebut.

Kata Kunci- Jalur Bus, QuantumGIS, GeoServer.

\section{PENDAHULUAN}

Transportasi merupakan perpindahan manusia atau barang dengan menggunakan kendaraan atau alat lain dari dan ke tempat-tempat yang terpisah secara geografis [6]. Salah satu perusahan transportasi negara yang mengelola bus adalah Djawatan Angkutan Motor Republik Indonesia (Damri). Produk transportasi ini menawarkan jasa angkutan diantaranya angkutan antar kota, angkutan barang, travel, bus kota dan angkutan bandara [5]. Kota Batam merupakan salah satu kota industri dan wisata yang terkenal di Indonesia, sehingga banyak kegiatan perekonomian yang juga mempengaruhi kegiatan di bidang transportasi umum. Transportasi umum yang disediakan oleh pemerintah Kota Batam dan Dinas Perhubungan adalah Bus Damri Trans Batam.

Berdasarkan data dari Perum Damri kurangnya informasi pelayanan bus damri kepada pengguna, baik itu warga kota batam dan juga para wisatawan yang datang ke kota batam menyebabkan Bus Damri Kota Batam kurang diminati dan jarang diketahui [8]. Hal demikian juga mempengaruhi sektor pariwisata kota Batam yang memanfaatkan angkutan umun sebagai salah satu modal transportasi yang mengantarkan wisatawan ke tempat tujuan wisata terutama pusat Kota Batam [6]. Kurangnya informasi Bus Damri Kota Batam dapat berdampak terhadap pilihan transportasi umum yang akan digunakan. Informasi penting yang terkait, seperti jam keberangkatan bus, tujuan atau jalur bus, halte pemberhentian bus dan jarak antara Halte Damri yang satu dengan yang lainya juga waktu tempuh yang digunakan, 
dapat memberikan dampak positif yang membuat masyarakat merasa puas akan informasi dan juga pelayanan mengenai Bus Damri sehingga dapat dijadikan sebagai transportasi umum sehari-hari.

Teknologi informasi saat ini sangat berpengaruh terhadap setiap aktivitas manusia diberbagai level bisnis, sehingga dalam kegiatan bisnis transportasi penting untuk memanfaatkan teknologi komputasi dalam menggambarkan informasi spasial atau keruangan dalam bentuk Sistem Informasi Geografis (SIG). Kegiatan transportasi yang baik haruslah memiliki informasi yang lengkap, tepat, cepat dan akurat serta dapat memenuhi kepuasan pelanggan [1],[2],[10],[13].

WebGIS memungkinkan solusi alternatif untuk menyampaikan informasi spasial dari jalur atau rute yang disesuaikan dengan kebutuhan pengguna transportasi Bus Damri di Kota Batam sehingga membantu masyarakat dalam mencari jadwal keberangkatan, jalur yang akan dituju dalam bentuk peta yang dapat di download oleh pengguna dan juga menampilkan setiap halte pemberhentian terdekat dari masing-masing rute.

\section{TinjauAn Pustaka}

\section{A. Sistem Informasi Geografis}

SIG merupakan suatu kumpulan yang terorganisir dari perangkat keras komputer, perangkat lunak, data geografi, dan personil yang dirancang secara efisien untuk memperoleh, menyimpan, memperbaharui, memanipulasi, menganalisis dan menampilkan semua bentuk informasi yang berreferensi geografi [4]. SIG mampu membantu dalam pemecahan masalah dengan cara menampilkan data menggunakan cara yang mudah dipahami dan hasilnya mudah disebarluaskan. Data berorientasi geografis, memiliki sistem koordinat tertentu sebagai dasar referensi yang terdiri dari:

1) Informasi spasial berupa data layer yang menampilkan informasi lintang dan bujur, termasuk diantaranya informasi datum dan proyeksi.

2) Informasi deskriptif atau informasi non spasial, suatu lokasi yang mempunyai beberapa atribut atau properti yang berkaitan dengannya; contohnya jenis vegetasi, populasi, luasan dan lain-lain. [3]

Data spasial direpresentasikan ke dalam dua format, yaitu data vector dan data raster. Data vector merupakan representasi bumi ke dalam kumpulan titik, garis, area dan nodes. Data raster merupakan data hasil dari sistem penginderaan jauh. Pada data raster, objek geografis direpresentasikan sebagai struktur sel grid yang disebut dengan piksel.

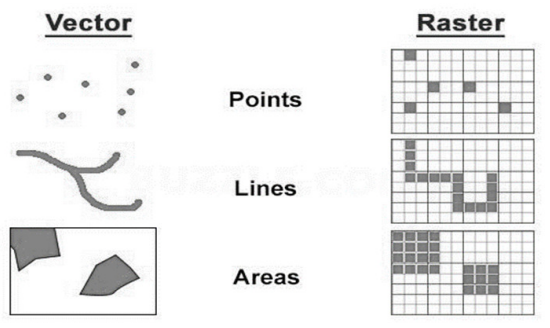

Gambar. 1 Data Vektor dan Data Raster (Sumber: Buzzle.com [10])

Digitasi peta dapat dilakukan dengan tiga cara point, lines dan polygon. Point atau titik digunakan untuk merepresentasikan lokasi objek gedung, bangunan atau lokasi tertentu. Lines atau garis digunakan untuk merepresentasikan sungai, jalan, jalur, dll. Terakhir polygon digunakan untuk merepresentasikan area yang memliki luas dan panjang keliling seperti wilayah pulau, propinsi, kecamatan, dll. Sumber data spasial didapat dari data penginderaan jauh, peta analog, pengukuran lapangan, data GPS dan data statistik tertentu.

\section{B. Sistem Referensi Koordinat}

Objek-objek spasial bereferensi spasial geografis, sehingga bukan sistem lokal atau bahkan sembarang. Untuk memahami referensi geografis, transformasi bentuk bumi dan sistem koordinat perlu mengenal datum. Ketika ingin memetakan objek-objek seperti sungai, jalan dan bangunan maka perlu menentukan garis lintang dan garis bujur, datum mampu menentukan persis orientasi dan asal-usul garis lintang dan bujur relative terhadap pusat bumi atau speroid. Sistem referensi koordinat yang digunakan adalah Datum WGS84 global (World Geodetic System of 1984).

\section{Quantum GIS}

Quantum GIS (QGIS) merupakan software digitasi untuk data spasial keruangan yang bersifat open source dan user friendly, dengan lisensi dibawah GNU General Public License. QGIS merupakan proyek tidak resmi dari Open Source 
Geospatial Foundation (OSGeo). QGIS dapat dijalankan pada versi sistem operasi Linux, Window dan Mac, serta mendukung banyak tipe format dan fungsionalitas data vector, raster dan basis data.

\section{Web GIS}

Pengembangan aplikasi GIS mengarah ke pengembangan berbasis web. Artinya GIS memanfaatkan jaringan internet sebagai media komunikasi yang berfungsi untuk mendistribusikan, mempublikasikan dan mengintegrasikan informasi dalam bentuk teks, peta digital serta mampu menjalankan fungsi analisis dan query [7]. Dengan menyajikan dalam bentuk web sehingga tidak tergantung platform atau sistem operasi tertentu dan dapat diakses secara luas kapanpun dan dimanapun. Untuk dapat melakukan komunikasi dengan komponen yang berbeda dilingkungan web maka dibutuhkan sebuah web server.

\section{E. Geoserver}

Geoserver merupakan software open source yang memungkinkan pengguna melakukan sharing dan editing terhadap data geospasial. Geoserver menggunakan bahasa pemograman Java dan menerapkan protokol web standar terbuka dari Open Geospatial Consortium (OGC) [9]. File spasial yang digunakan adalah shapefile. Shapfile merupakan kumpulan beberapa file dengan 3 ekstensi utama yaitu;

1) *.shp - shape format, menyimpan data fitur geometri

2) *.shx - shape index format, indek dari fitur geometri sehingga memudahkan dalam proses pencarian

3) *.dbf - attribute format, berisi tabel atribut dari tiap fitur dalam dBase IV format.

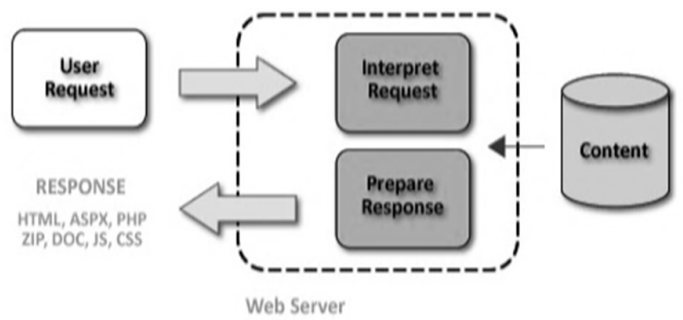

Gambar. 2 Request dan Respon Web Server (Sumber: presentations.opengeo.org [9])

Geoserver menerapkan Web Map Service (WMS) standar dalam pemanggilan ekstensi file berupa data geografis, permintaan dikirim ke server, ditafsirkan dan direspon. Selain itu geoserver memenuhi persyaratan Web Feature Service (WFS) dan Web Service Coverage (WCS).

\section{Metode Penelitian}

Metode dalam pengembangan perangkat lunak menggunakan sistem sekuensial linear atau yang biasa disebut metode waterfall. Pengembangan dimulai dari tahap perencanaan, analisis kebutuhan pengguna, desain, kode, pengujian dan implementasi hasil, secara keseluruhan diilustrasikan pada gambar 3. Tahap perencanaan melakukan survei lokasi untuk mencari titik koordinat dan jalur bus. Selain itu survei analisis kebutuhan pengguna baik dari kebutuhan fungsional maupun non fungsinonal, kebutuhan perangkat lunak dan perangkat keras yang akan digunakan baik dalam pengembangan maupun implementasi sistem. Pengujian sistem dilakukan dengan cara memeriksa dan mengamati hasil eksekusi melalui data uji dari perangkat lunak yang telah dikembangkan. 


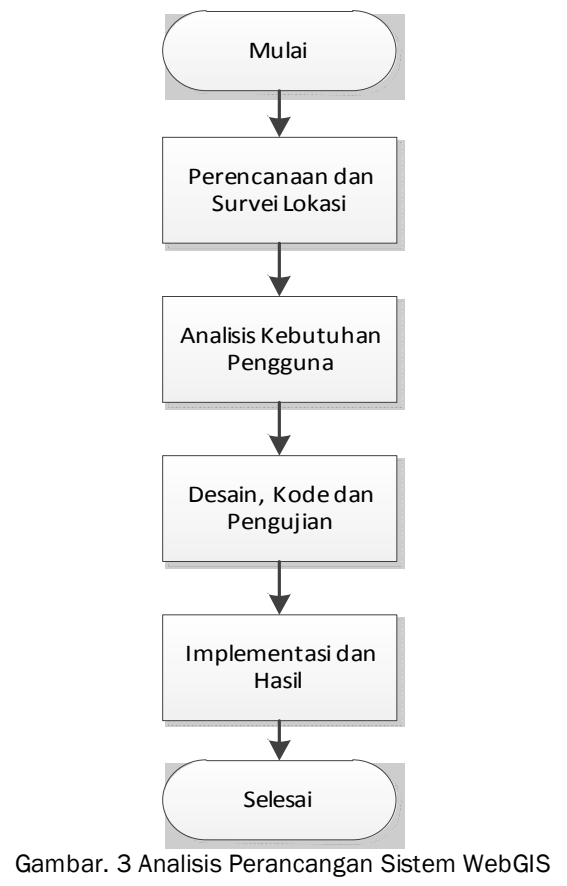

\section{A. Analisis Perancangan WebGIS}

Sistem akan menampilkan informasi mengenai peta jalur bus, halte bus, trayek bus, tarif bus dan informasi terkait Perum Damri Kota Batam. Interaksi sistem antara client (pelanggan) dan server dalam bentuk web browser dengan protocol http. Web browser pada sisi client meminta atau request ke Web Server lalu diteruskan ke server Spasial Database dan komponen GIS hasil dari digitasi yang dioverlayerkan.

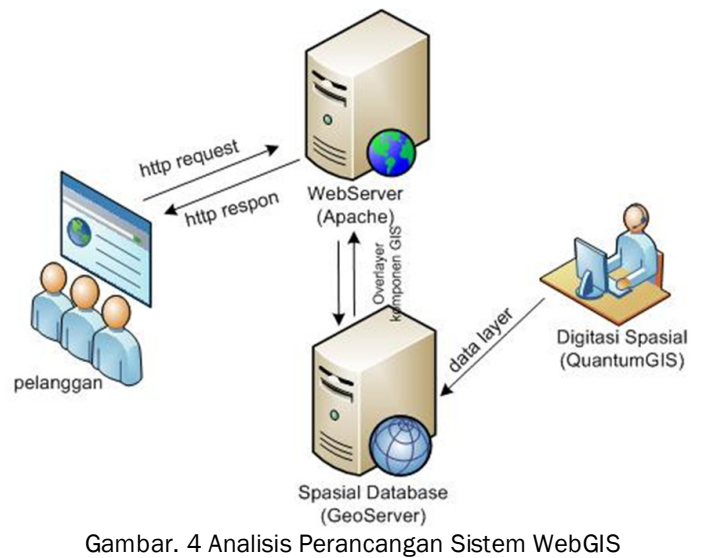

Artinya Web Server akan mengambil permintaan client browser dan menterjemahkan serta mengembalikan sebuah respon pada tampilan layar client browser. Hasil pemrosesan akan dikembalikan dalam bentuk file HTML sebagai http respon. Digitasi spasial dilakukan secara manual program dengan software Quantum GIS dan database spasial menggunakan Geoserver.

\section{B. Desain Use Case Diagram WebGIS}

Use case diagram merupakan diagram penggambaran bentuk interaksi dari setiap aktor dengan sistem yang berjalan. Sistem berbasis webGIS terdapat dua aktor yang berperan dalam sistem yang dirancang yaitu administrator dan pengguna. Dimana aktor pengguna dapat mencari rute Bus Damri yang akan dituju dan dapat mendownload peta dalam 
bentuk data raster. Sistem dapat menampilkan informasi mengenai Bus Damri Kota Batam dan menampilkan peta geografis yang memuat jalur, koridor atau halte serta legenda lain yang mendukung. Aktor administrator dapat melakukan kelola data Bus Damri berupa informasi bus, informasi jalur atau rute, informasi halte dan jarak yang di tempuh.

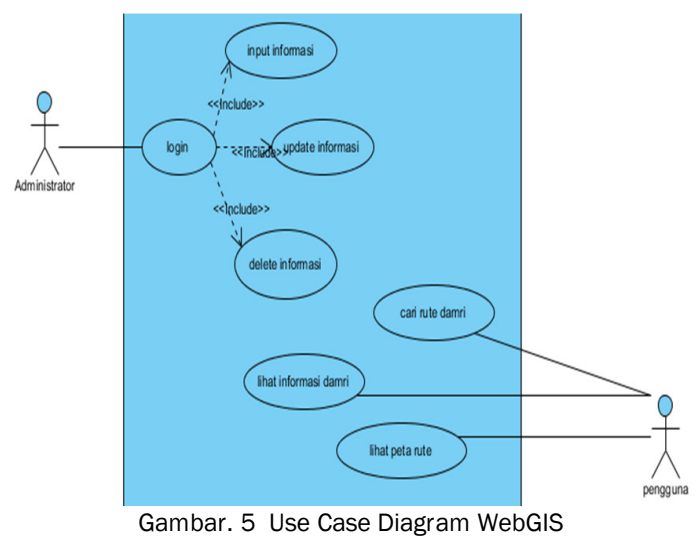

\section{Tahap Digitasi Quantum GIS}

Secara geografis kota Batam terletak pada koordinat 0.25'29"-1.15'00" Lintang Utara dan 103.34'35"- 104'.26'04" Bujur Timur. Dengan luas wilayah keseluruhan kota Batam mencapai 2.950 km2. Tahap digitasi pada Quantum GIS dimulai dengan melakukan import data raster yang diperoleh melalui google map atau penginderaan jauh dengan mengambil area Pulau Batam.

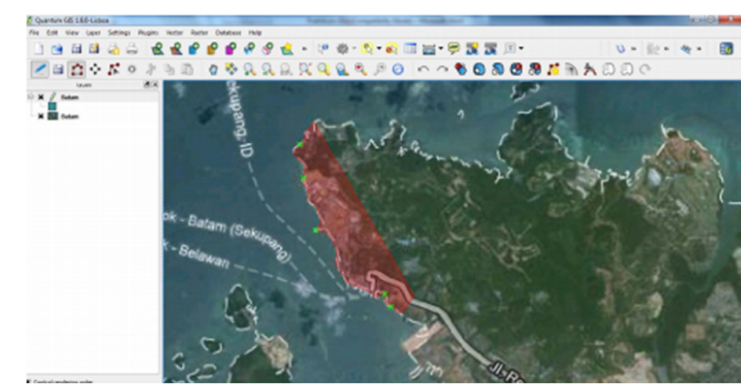

Gambar. 6 Digitasi Peta

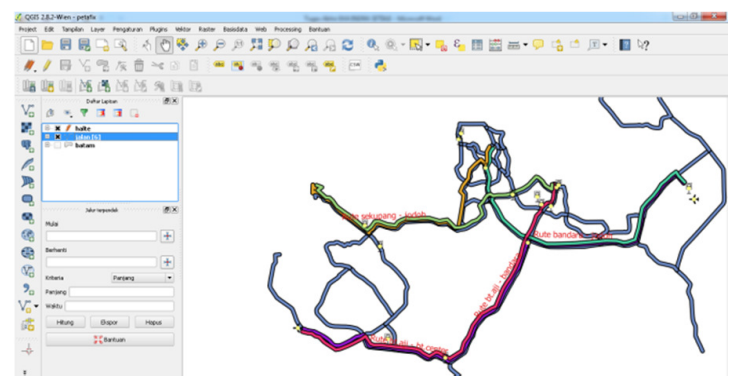

Gambar. 8 Hasil Digitasi Line

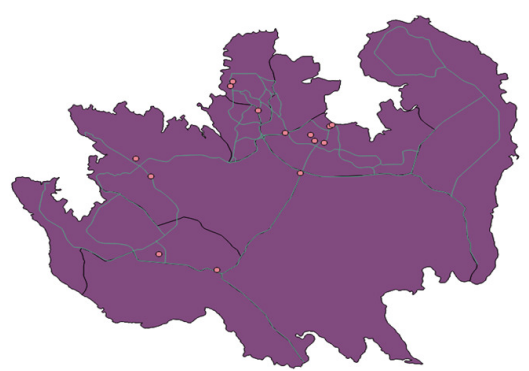

Gambar. 7 Hasil Digitasi Poligon

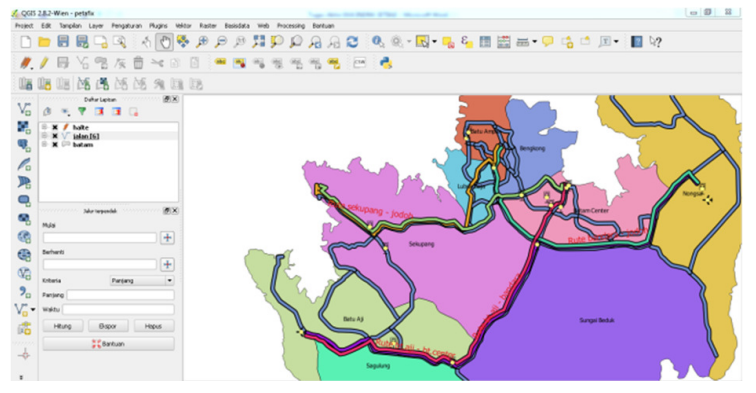

Gambar. 9 Hasil Digitasi Poin, Line dan Poligon

Hasil dari digitasi berupa file *.shp atau shapfile yang merupakan representasi dari poligon, line dan poin. Digitasi poligon menampilkan peta pulau batam dengan kecamatan. Digitasi line menampilkan peta jalan dan jalur bus. Digitasi titik menampikan lokasi dan tempat pemberhentian (halte) bus. Penentuan koordinat dilakukan menggunakan teknologi GPS dengan mendaftarkan titik-titik koordinat dengan bantuan google map untuk pencarian beberapa lokasi. Data koordinat dari Halte Kota Batam yang akan digunakan untuk menampilkan posisi dari halte tersebut. 
TABEL 1. DAFTAR KOORDINAT HALTE dAN JALUR BUS

\begin{tabular}{|c|l|l|c|c|}
\hline ID & \multicolumn{1}{|c|}{ Nama } & \multicolumn{1}{|c}{ Rute } & Longitude & Latitude \\
\hline 1 & Halte Jodoh & Jodoh-Bandara & 1.155 & 104.002 \\
\hline 2 & Halte Bt.Ampar & Jodoh-Bandara & 1.158 & 104.003 \\
\hline 3 & Halte Lbk. Baja & Btm.Center-Sekupang & 1.140 & 104.016 \\
\hline \hline 4 & Halte Gelael & Btm.Center-Sekupang & 1.126 & 104.030 \\
\hline 5 & $\begin{array}{l}\text { Halte Pelabuhan } \\
\text { Btm.Centr }\end{array}$ & Bt.Aji-Btm Center & 1.130 & 104.053 \\
\hline \hline 6 & $\begin{array}{l}\text { Halte Transfer Poin } \\
\text { Btm.Center }\end{array}$ & $\begin{array}{l}\text { Bt.Aji-Btm Center/Btm } \\
\text { Center-Sekupang }\end{array}$ & 1.131 & 104.054 \\
\hline 7 & Halte Yosudarso & Btm.Center-Sekupang & 1.125 & 104.043 \\
\hline 8 & Halte Politeknik & $\begin{array}{l}\text { Bt.Aji-Btmcenter/Btm } \\
\text { Center-Bt.Aji }\end{array}$ & 1.120 & 104.050 \\
\hline 9 & Halte Frengky & $\begin{array}{l}\text { Bt.Aji-Btmcenter/Btm } \\
\text { Center-Bt.Aji }\end{array}$ & 1.121 & 104.045 \\
\hline 10 & Halte Sekupang & Btm.Center-Sekupang & 1.110 & 103.953 \\
\hline 11 & Halte Tiban Koprasi & Btm.Center-Sekupang & 1.099 & 103.961 \\
\hline 13 & Halte Batu Aji & $\begin{array}{l}\text { Btm.Center-Bt.Aji/Bt.Aji- } \\
\text { Btm.Center }\end{array}$ & 1.051 & 103.965 \\
\hline \hline 14 & $\begin{array}{l}\text { Halte Fanindo } \\
\text { Transfer Poin }\end{array}$ & $\begin{array}{l}\text { Btm.Center-Bt.Aji/Bt.Aji- } \\
\text { Btm.Center }\end{array}$ & 1.041 & 103.995 \\
\hline 15 & Halte Kepri Mall & $\begin{array}{l}\text { Btm.Center-Bt.Aji/Bt.Aji- } \\
\text { Btm.Center }\end{array}$ & 1.101 & 104.038 \\
\hline
\end{tabular}

\section{B. Tahap Pengunggahan Geoserver}

Pengunggahan data spasial dilakukan pada server lokal dengan memindahkan file *.shp hasil digitasi pada Quantum GIS pada direktori geosever (... \Geoserver\data_dir). Pada browser ketikkan http://localhost:8080/geoserver/web dan masukkan username "admin" dan password "geoserver". Ciptakan sebuah ruang kerja (workspace) untuk shapfile, yang digunakan untuk kelompok lapisan overlayer lapisan yang sama. Untuk membuat ruang kerja maka akan diminta untuk memasukkan nama ruang kerja dan namespace URI. Sebuah Namespace URI (Uniform Resource Identifier) biasanya URL yang terkait.

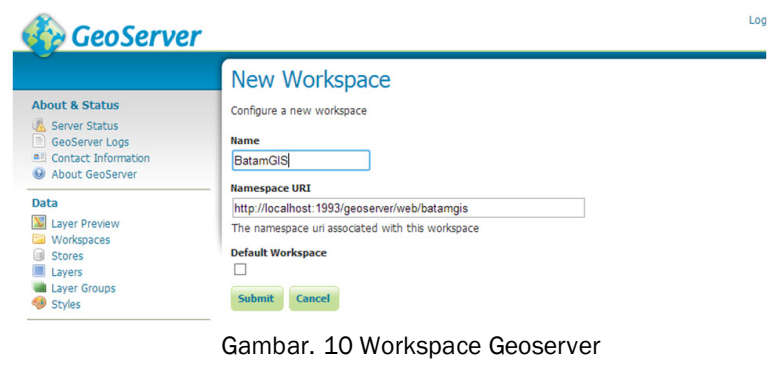

Setelah membuat workspace, selanjutnya mengimport data shapfile dengan memilih shapfile-ESRI(tm) Shapfile (.shp). Arahkan ke halaman New Layer untuk mengkonfigurasi layer batam dan sistem referensi koordinat diisi secara manual dengan EPSG:4326, lalu mengisikan kota layer (bounding boxes) dengan mengklik Compute From Data dan Compute From Native Bounds, sehingga akan terisi secara otomatis.

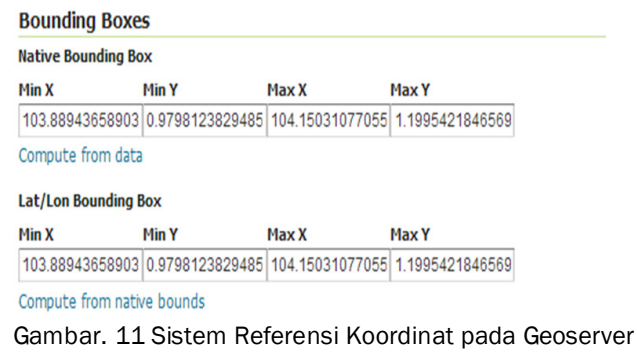

Untuk memverifikasi bahwa layer batam telah dipublish dengan benar, maka dapat dilihat pada Layer Preview. Sebuah openlayer peta pada halaman baru akan menampilkan shapfile yang dapat dilihat preview untuk memoerbesar dan memperkecil serta menggeser dataset hingga menampilkan atribut fitur. 


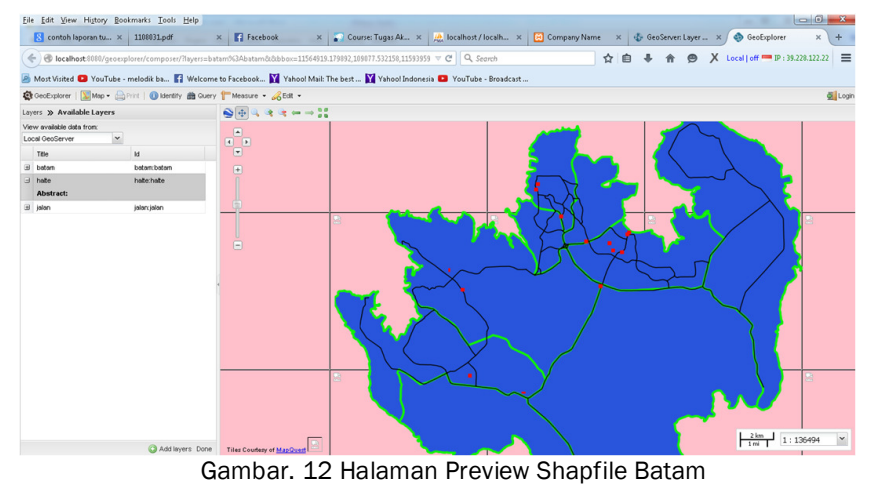

Geoserver membutuhkan format *.shp untuk menampilkan layer peta, dan memberikan link pada webGIS Bus Damri Kota Batam. Tentu saja semua data tersebut tidak langsung digunakan, tetapi perlu dilakukan penyesuaian dahulu baik mengenai jenis data, atribut yang ada, sampai proses penggabungan data (overlayer). Oleh karena itu, perlu dilakukan pemrosesan data awal.

\section{IMPLEMENTASI DAN HASIL}

Implementasi basis data yang dihasilkan dengan nama basis data db_bus yang memiliki atribut no trayek, merk bus, jenis dan seat, rute, fasilitas, halte line. Implementasi antar muka sistem yang dihasilkan berbasis web dengan tampilan sebagai berikut. Implementasi tabel basisdata yang dihasilkan dalam perancangan sistem sebagai berikut.

TABEL 2. BASIS DATA BUS

\begin{tabular}{|c|l|l|l|l|}
\hline No & \multicolumn{1}{|c|}{ Nama Fleld } & \multicolumn{1}{|c|}{ Tipe } & Vol & Ket \\
\hline 1 & No Terayek & Int & 50 & Primary Key \\
\hline 2 & Merk bus & Varchar & 50 & \\
\hline 3 & Jenis dan seat & Varchar & 80 & \\
\hline 4 & Rute & Varchar & 80 & \\
\hline 5 & Fasilitas & Varchar & 50 & \\
\hline 6 & Halte Line & Varchar & 80 & \\
\hline
\end{tabular}

Setelah pengguna dihadapkan pada antarmuka halaman utama, pengguna dapat memilih menu informasi rute. Pada halaman ini menampilkan informasi mengenai bus, rute dan peta kota batam yang memuat poin-poin halte. Untuk mengetahui informasi rute dapat dilakukan dengan mengarahkan atau klik poin-poin pada halte tersebut. Tampilan antarmuka halaman informasi halte dan jalur bus damri kota batam yang disajikan dalam bentuk peta kota batam berbasis webgis.
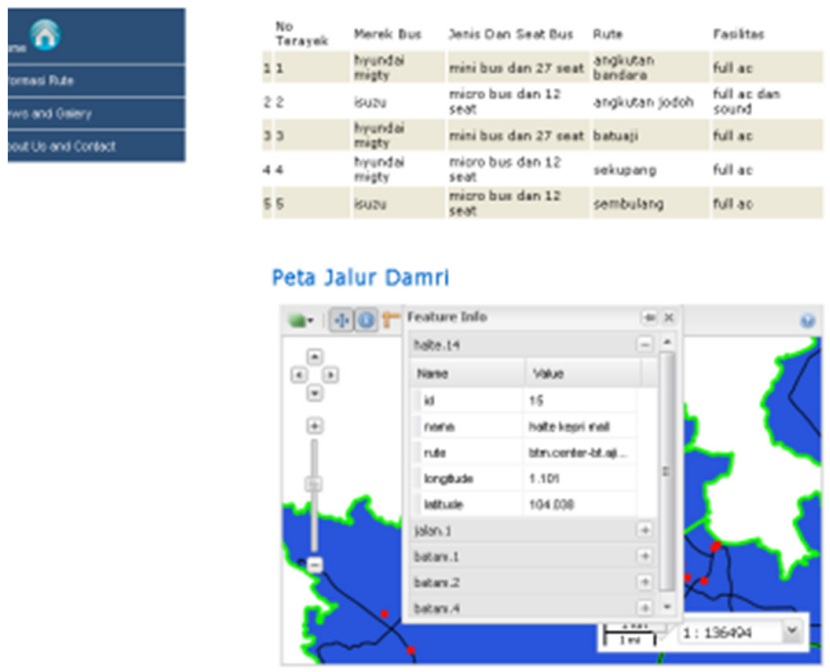

Gambar. 13 Halaman Informasi Jalur Bus 
A. Kesimpulan

Kesimpulan dari perancangan Pemetaan Jalur Bus Damri Kota Batam Berbasis WebGIS adalah sebagai berikut:

1) Telah dirancang dan dibangun pemetaan jalur bus umum yang menampilkan informasi halte, jalur dan menampilkan informasi bus sesuai dengan kebutuhan pengguna.

2) Dengan menggunakan basisdata spasial Geoserver mampu menampilkan hasil digitasi peta dari QuantumGIS dengan format shapfile. Informasi yang ditampilkan berupa jalur atau rute, tempat pemberhentian bus (halte), jarak tempuh dan informasi spasial lainnya.

3) Selain informasi spasial jadwal keberangkatan dan informasi berikatan dengan layanan Bus Damri dapat diperoleh dengan mudah dengan mengakses diberbagai platform sistem operasi karena dikembangkan dengan menggunakan teknologi berbasis web.

B. Saran

Saran yang mungkin dapat dikembangkan selanjutnya adalah memadukan data dari informasi transportasi darat, laut dan udara yang ada di Kota Batam sehingga informasi seputar transportasi yang diperoleh pengguna atau wisatawan dapat lebih terintegrasi.

\section{UCAPAN TERIMA KASIH}

Penulis mengucapkan terima kasih untuk Pusat Penelitian dan Pengabdian Masyarakat (P2M) Politeknik Negeri Batam.

\section{REFERENSI}

[1] B. Chandra, Fitri, E. P. Widiyanto. 2014. Rancang Bangun Sistem Informasi Geografis Rute Angkutan Kota di Palembang. Seminar Perkembangan dan Hasil Penelitian IImu Komputer (SPHP-ILKOM).

[2] F. Juniardi, H. Azwansyah. Penyusunan Sistem Informasi Geografis Infrastruktur Transportasi Kabupaten Kapuas Hulu Berbasis Web. Jurnal Elkha Vol.6, No.1 Maret 2014.

[3] O. Patrick, dan A. Reno, 2012. Tutorial ArcGIS10 Tingkat Dasar. Bappeda NTB.

[4] ESRI, 1989. Users Guide ARC/INFO Vol. 2. Commond References. The Geographic Information Sistem Software. Environmental System Research Institute, Inc. Redlands, California

[5] Fonseca, F. dan Davis, C. 1999. Using the Internet to Access Geographic Information: An OpenGIS Prototype. in: M. Goodchild, M. Egenhofer, R. 1Fegeas, and C. Kottman (Ed.), Interoperating Geographic Information Systems. Kluwer Academic Publishers, Norwell, MA

[6] Steenbrink, P.A. 1974, Optimization of Transport Networks, J. Wiley, New York.

[7] E. Prahasta. 2009 Sistem Informasi Geografis, Bandung: Penerbit Informatika.

[8] Website DAMRI tersedia www.damri.co.id

[9] Website Quantum GIS dan Geoserver tersedia www.qgis.org, presentations.opengeo.org dan www.geoserver.org

[10] B. 2014. Swetha Difference Between Raster and Vector Graphics. Tersedia di www.buzzle.com/articles/difference-between-raster-and-vectorgraphics.html

[11] E. K. Morlock, 1998. Pengantar Teknik dan Perencanaan Transportasi, Erlangga, Jakarta.

[12] A. Kadir. 2003. Pengenalan Sistem Informasi. Yogyakarta: ANDI Yogyakarta.

[13] Rastuti, L. A. Abdillah, E. P. Agustini. Sistem Informasi Geografis Potensi Wilayah Kabupaten Banyuasin Berbasis Web. Student Colloquium Sistem Informasi dan Teknik Informatika (SC-SITI), Palembang, 2015. 